\title{
Küçük Hücreli Dışı Akciğer Kanserli Kranial Metastaz Gelişen Olgularda Metastazektomi Yapılan ve Sistemik Tedavi Alan Hastaların Retrospektif Değerlendirilmesi
}

\author{
Adem DELİGÖNÜL ${ }^{1}$, Ahmet BEKAR ${ }^{2}$, Hüseyin MELEK ${ }^{3}$, Erdem ÇUBUKÇU ${ }^{1}$, \\ Süreyya SARIHAN ${ }^{4}$, Ahmet Bilgehan ŞAHIN ${ }^{1}$, Türkkan EVRENSEL ${ }^{1}$
}

1 Bursa Uludağ Üniversitesi Tıp Fakültesi Tıbbi Onkoloji Bilim Dalı, Bursa.

2 Bursa Uludağ Üniversitesi Tıp Fakültesi Beyin ve Sinir Cerrahisi Anabilim Dalı, Bursa.

3 Bursa Uludağ Üniversitesi Tıp Fakültesi Göğüs Cerrahisi Anabilim Dalı, Bursa.

4 Bursa Uludağ Üniversitesi Tıp Fakültesi Radyasyon Onkolojisi Anabilim Dalı, Bursa.

\section{ÖZET}

Küçük hücreli dışı akciğer kanseri (KHDAK)'nin en sık metastaz yaptığı organlardan biri beyindir. Beyin metastazı olan hastalar tedavi edilmediğinde ortalama yaşam süresi aylarla sınırlıdır. Bu çalışmanın amacı beyin metastazı yapmış evre 4 KHDAK hastalarda beyin metastazı için cerrahi tedavi uygulamasının onkolojik sonuçlarını göstermektir. Kliniğimizde 2004-2012 yılları arasında KHDAK tanısı konan ve BM nedeniyle cerrahi tedavi uygulanan 59 hastanın verileri prospektif olarak kaydedildi ve retrospektif olarak incelendi. Hastaların cerrahi ve onkolojik sonuçları irdelendi. Sağ kalım süresi beyin metastazı tanısı konulduğu tarih ile ölüm tarihi veya mevcut en son takip arasındaki zaman olarak hesaplandı. Hastaların 51'i erkek, 8'i kadın, ortalama yas 56.92 (37-81) yıl idi. Cerrahi olarak 55 hastaya total eksizyon, 4 hastaya subtotal eksizyon yapıldı. Ameliyat sonrası mortalite saptanmadı. Patolojik inceleme sonucunda 55 hastada cerrahi sınırlar tümörsüz, 4 hastada ise cerrahi sınır mikroskobik pozitif olarak bildirildi. Ameliyat sonrasında tüm hastalara palyatif kranial radyoterapi ve sistemik kemoterapi verildi. 11 hastaya(\%18,6) akciğerdeki primer kitleye kemoradyoterapi verildi. 8 hastaya akciğere yönelik cerrahi lobektomi, 7 hastaya pnömonektomi uygulandı. Medyan genel sağkalım süresi $12,00(1,0-159,0)$ aydı. Hastaların 12,24 ve 60 aylık sağkalım oranları sırasıyla \%47.5, \%28.8 ve \%13.5 olarak bulundu. Üç olguda ise 10 yılın üzerinde genel sağ kalım elde edildi. Beyin metastazı yapmış KHDAK'lu hastalarda kranial metastazektomi hastaların sağkalımına olumlu katkı sağlayabilir.

Anahtar Kelimeler: Akciğer Kanseri. Beyin Metastazı.

Retrospective Evaluation of Metastasectomy and Systemic Treatment in Patients with Non-Small Cell Lung Cancer and Cranial Metastasis

\begin{abstract}
The brain is one of the organs that non-small cell lung cancer (NSCLC) metastasizes most frequently. The life expectancy is limited to months in patients with brain metastasis (BM), which is not treated. This study aims to show the oncological outcomes of surgical treatment of cranial lesion in patients with stage 4 NSCLC. The data of 59 patients who were diagnosed with NSCLC and underwent surgical treatment of BM between 2004 and 2012 in our clinic were prospectively recorded and analyzed retrospectively. The surgical and oncological outcomes of the patients were studied. Survival was calculated as the time between the diagnosis of BM and the date of death or the last followup. Fifty-one of the patients were male, and eight were female, and the median age was 56.9 (37-81) years. Fifty-five patients underwent total excision, and four patients underwent subtotal excision. No postoperative mortality was detected. As a result of the pathological examination, the surgical margins were reported as tumor-free in 55 patients, and microscopically positive in 4 patients. Palliative cranial radiotherapy and systemic chemotherapy were given to all patients after surgery. Eleven patients (18.6\%) underwent chemoradiotherapy to the primary mass in the lung. Lobectomy and pneumonectomy were performed in 8 and 7 patients. The median overall survival was 12.00 (1.0159.0) months. The 12,24 , and 60 -month survival rates of the patients were $47.5 \%, 28.8 \%$, and $13.5 \%$, respectively. In three cases, overall survival over ten years was obtained. Cranial metastasectomy may contribute positively to the survival of patients with NSCLC.
\end{abstract}

Keywords: Lung Cancer. Brain Metastasis.

Geliş Tarihi: 06.Mart.2020

Kabul Tarihi: 20.Mart.2020
Dr. Adem DELIGÖNÜL

Bursa Uludağ Üniversitesi Tıp Fakültesi Tıbbi Onkoloji Bilim

Dalı, Bursa.

Tel.:0530 8449232

E-posta:ademdeligonul@yahoo.com 
Küçük hücreli dışı akciğer kanseri (KHDAK), tüm akciğer kanserlerinin \%85-90'ını oluşturur ve hem kadın hem erkeklerde kansere bağlı ölümlerin önde gelen nedenidir. ${ }^{1} \mathrm{En}$ sık metastaz yaptığ 1 organlar beyin, kemik, karaciğer ve adrenal bezlerdir. Beyin metastazı, KHDAK hastalarının \%13-54'ünde görülür ${ }^{2}$. Beyin metastazı varlığında genel olarak prognoz kötüdür. Ancak medyan sağ kalım süresi 3 ila 14 ay arasında değişen ile heterojen bir gruptan oluşur. ${ }^{3}$ Cerrahi rezeksiyon, tüm beyin radyoterapisi (TBRT), sterotaktik radyocerrahi, sistemik kemoterapi önerilen tedavi yaklaşımlarıdır. Palyatif tedavinin sağ kalıma katkısı 1-2 ay, tek başına TBRT'nin 4-6 ay iken cerrahi rezeksiyonun sağ kalıma katkısının 10-24 ay olduğu yapılan çalışmalarla gösterilmiştir. ${ }^{4-6}$ Soliter BM olan olgularda, hem beyin hem de primer akciğerdeki tümörün tedavisi ile hastalarda uzun süreli sağkalımı bildiren birçok retrospektif çalışma yayınlanmıştır. ${ }^{7-10}$

Bu çalışmada beyin metastazı yapmış evre 4 KHDAK hastalarda beyin metastazı için cerrahi tedavi uygulanan hastalarımızın cerrahi ve onkolojik sonuçlarını saptamayı amaçladık.

\section{Hastalar ve Yöntem}

Çalışmaya Uludağ Üniversitesi Tıp Fakültesi 20204110 no'lu etik kurul onayıyla başlandı.

Çalışmamıza 2004-2012 yılları arasında BM yapmış evre 4 KHDAK tanısı konulan, ve Bursa Uludağ Üniversitesi Tıp Fakültesi Nöroşirurji Anabilim Dalı'nda cerrahi uygulanan sonrasında Radyasyon Onkoloji Anabilim Dalın'da radyoterapi ve Tibbi Onkoloji Bilim Dalı'nda sistemik kemoterapi uygulanan ve takipleri multidisipliner yapılan hastaların verileri prospektif olarak kayıt edildi ve retrospektif olarak incelendi. 51'i (\%86.4) erkek, 8'i(\%13.6) kadın toplam 59 hasta çalışma grubumuzu oluşturdu. Hastaların cinsiyet, tanı anında yaşı,şikayetleri, tümör lokalizasyonu, operasyon tipi, akciğer kanseri alt tipleri, aldığ onkolojik tedavileri analiz edildi.

BM tanısı aldığı andan ölüme kadar geçen zaman veya son kontrol tarihi ortalama genel sağ kalım hesaplanması için kullanıldı. Çalışmada verilerin istatiksel analizi SPSS sürüm 22.00 programı kullanılarak yapıldı. Çalışma verileri değerlendirilirken tanımlayıcı istatistiksel metotları (frekans, yüzde, ortalama, standart sapma) kullanıldı. Sağ kalım hızlarının tespitinde Kaplan-Meier sağkalım analizi kullanıldı. Tümör alt tiplerinin ve RT bölgelerinin sağkalım üzerine etkileri log-rank testi kullanılarak incelendi. Sonuçlar \%95 güven aralığında, $\mathrm{p}<0.05$ anlamlılık düzeyinde değerlendirildi.

\section{Bulgular ve Sonuç}

Olguların yaş ortalaması 56.92 (37-81) yıl; kadınların yaş ortalaması 58 , erkek olguların yaş ortalaması 56 yıldı. Olguların 16'sı (\%27.1) 50 yaş altında, 17'si
(\%28.8) 50-60 yaş arası, 20'si (\%33.8) 60-70 yaş arası, 6'sı (\%10.1) 70 yaş üzerindeydi. Hastaların tanı sırasında şikayetleri değerlendirildiğinde; en sık semptom baş ağrısıydı (\%30,5). Baş ağrısını sıklık sırasına göre; hemiparezi, dengesizlik ve nöbet izlemekteydi. Birden fazla nörolojik semptom 13 hastada gözlenirken; iki hasta ise asemptomatikti. Asemptomatik olgular, rutin tarama sirasinda tespit edilen olgulardı. Hastaların 41'inde (\%69.5) adenokarsinom, 16 (\%27.1) hastada skuamöz hücreli karsinom ve 2 (\%3.4) hastada büyük hücreli karsinom mevcuttu. 55 hastaya total, 4 hastaya ise subtotal kitle eksizyonu yapıldı. Postoperatif dönemde 48 hastaya sadece kranial, 11 hastaya ise hem kranial hem de akciğerdeki primer kitleye RT uygulandı. Ayrıca hastalara anti ödem tedavisi uygulandı. Tüm hastalar platin bazlı kemoterapi aldı.(Tablo.I). 15 hastaya akciğerdeki primer kitleye yönelik cerrahi işlem yapıldı.

Tablo I. Demografik, Klinik ve Patolojik Özellikleri

\begin{tabular}{|c|c|c|}
\hline & & N (\%) \\
\hline $\begin{array}{l}\text { Yaş (Ortalama } \\
\pm \text { Standart } \\
\text { Sapma) }\end{array}$ & & $56,9 \pm 9,7$ \\
\hline & Kadın & $8(13,6)$ \\
\hline Cinsiyet & Erkek & $51(86,4)$ \\
\hline & Baş Ağrısı & $18(30,5)$ \\
\hline & Hemiparezi & $12(20,3)$ \\
\hline Şikâyet & Dengesizlik & $8(13,6)$ \\
\hline & Nöbet & $6(10,2)$ \\
\hline & Birden Fazla Nörolojik Semptom & $13(22,0)$ \\
\hline & Asemptomatik & $2(3,4)$ \\
\hline & Hipertansiyon & $8(13,6)$ \\
\hline & Diyabetes Mellitus & $3(5,1)$ \\
\hline Ek Hastalık & Koroner Arter Hastalığı & $1(1,7)$ \\
\hline & Birden Fazla Ek Hastalık & $6(10,2)$ \\
\hline & Ek Hastalık Yok & $41(69,4)$ \\
\hline Son Durum & Yaşıyor & $3(5,1)$ \\
\hline SOII Duiluil & Ex & $56(94,9)$ \\
\hline & Adenokarsinom & $41(69,5)$ \\
\hline Tümör Alt Tipi & Skuamöz Hücreli Karsinom & $16(27,1)$ \\
\hline & Büyük Hücreli Karsinom & $2(3,4)$ \\
\hline & Paryetal Lob & $18(30,4)$ \\
\hline & Frontal Lob & $17(28,8)$ \\
\hline Tümör Lokali- & Serebellum & $8(13,6)$ \\
\hline zasyonu & Pons & $7(11,9)$ \\
\hline & Oksipital Lob & $5(8,5)$ \\
\hline & Temporal Lob & $4(6,8)$ \\
\hline & Total Eksizyon & $55(93,2)$ \\
\hline Operasyon & Subtotal Eksizyon & $4(6.8)$ \\
\hline Extrakranial & Var & $48(81,4)$ \\
\hline metastaz & Yok & $11(18,6)$ \\
\hline & Karboplatin + Paklitaksel & $30(50.8)$ \\
\hline SIIrincl Seçım & Sisplatin + Dosetaksel & $13(22.1)$ \\
\hline $\begin{array}{l}\text { Kemoterapi } \\
\text { Rejimi }\end{array}$ & Sisplatin + Etoposid & $9(15,2)$ \\
\hline & Sisplatin + Gemsitabin & $7(11,9)$ \\
\hline & Aldı & $59(100)$ \\
\hline Radyoterapı & Almadı & $0(0)$ \\
\hline Radyoterapi & Sadece Kranial & $48(81.3)$ \\
\hline Bölgesi & Kranial ve Akciğer & $11(18,7)$ \\
\hline
\end{tabular}




\section{Akciğer Kanseri Kranial Metastaz}

Hastaların medyan genel sağkalım süresi 12 (1.0159.0) aydı (Şekil-1). Altı, 12, 24, 36 ve 60 aylık sağ kalım oranları sırasıyla \%74.6, \%47.5, \%28.8, \%18.6 ve $\% 13.5$ olarak bulundu. Kadın cinsiyette genel sağ kalım 16 aydı fakat cinsiyetin sağkalıma etkisi istatistiksel anlamlı değildi ( $p=0.41)$. Kanser alt tipine göre yapılan Kaplan-Meier analizinde genel să̆ kalım süreleri adenokarsinom ve skuamöz hücreli karsinom gruplarında benzer saptand $1(p=0.49)$. Sadece kranialRT alan hastalar ile hem kranial hemde akciğerde primer tümöre RT alan hastaların genel sağkalım süreleri karşılaştırıldığında; her iki bölgeye RT alan hastaların medyan sağ kalım süreleri daha uzun olsa da istatistiksel anlamlı değildi $(p=0.172)$ (Şekil-2). Post op kısa sürede kaybedilen hastalar yaşlı, komorbiditesi birden fazla olan ve kranial dışı metastaz progresyonu olan hastalard1.

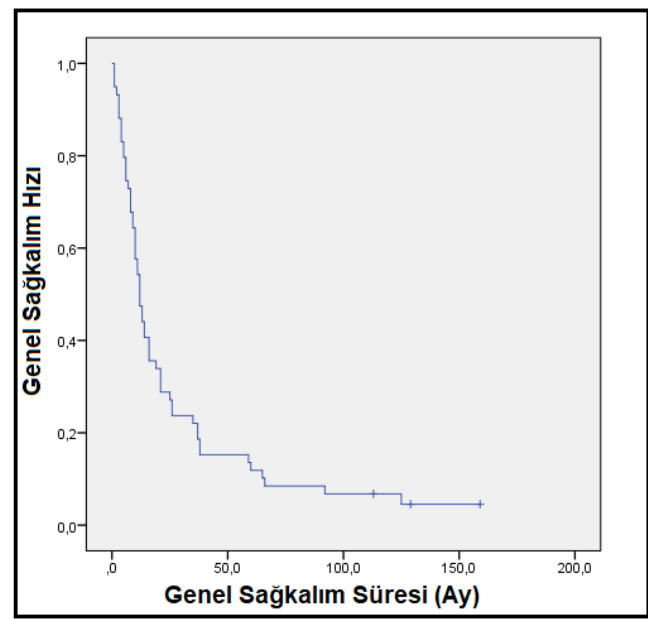

Şekil 1:

Genel Să̆ kalım

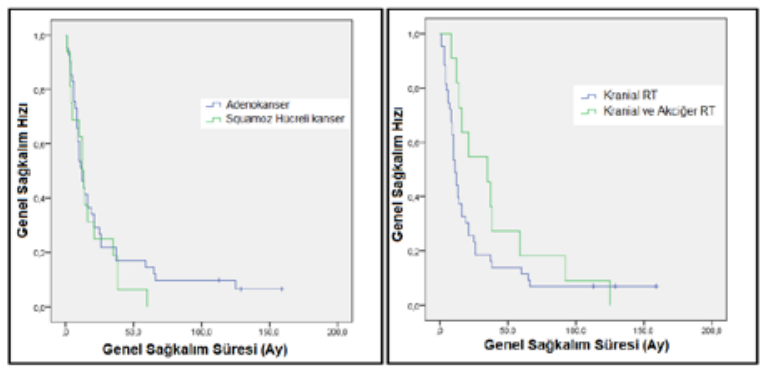

Sekil 2:

Tümör alt tip ve RT lokalizasyonuna göre sağ kalım

\section{Tartışma}

Beyin metastazı gelişen KHDAK'i genellikle kötü prognoza sahiptir ve yaşam kalitesini olumsuz yönde etkilemektedir.

İnal ve $\operatorname{ark}^{11}$. ülkemizde yaptığı çok merkezli çalışmada metastatik KHDAK'inde ekstrakranial sistemik hastalık kontrolü olanlarda kranial metastazektomi yapılmasının, metastfazektomi yapılmayanlara göre genel sağ kalımı uzattığını gösterdiler.

Bonnette ve $\operatorname{ark}^{12}$. yaptığı çok merkezli retrospektif çalışmada kranial metastazektomi yapıldı̆̆ itibaren yapılan sağ kalım analizinde 12 aylık sağ kalım oranı \%56, 24 aylık sağ kalım oranı $\% 28$ ve 60 aylık sağ kalım oranı \%11 olarak bildirilmiştir. Bizim çalışmamızda ise 12,24 ve 60 aylık sağ kalım oranları sirasiyla \%47.5, \%28.8 ve \%13.5 olarak bulundu. 24 ve 60 aylık sağkalım oranları benzer olmakla birlikte 12 aylık sağ kalım oranı çalışmamızda daha düşüktür. $\mathrm{Bu}$ farklılık hasta yaşı ve diğer komorbit nedenlere bağlı olabilir.

Niemiec ve $\operatorname{ark}^{13}$ yaptığı çalışmada sadece BM gelişen hastalardan metastazektomi yapılmayanlarının 3 yıllık sağ kalım oranının yalnızca $\% 2$ olduğu gösterdiler. Metastazektomi yapılanlar ve primer tümörü kontrol altında olanlarda bu oranın daha yüksek olduğunu bildirdiler. Bizim çalışmamızda ise 3 yıl ve üzerinde hayatta kalan hasta oranı \%18.6 olduğu görüldü. Niemiec ve arkadaşlarının çalışmasına göre bizim olgularımızda 3 yıllık sağ kalım oranı daha yüksekti.

Iwasaki ve $\operatorname{ark}^{14}$ yaptığı retrospektif çalışmada da, BM gelişen ve başka ekstrakranial tutulumu olmayan 70 KHDAK hastaya metastazektomi ve primer akciğer tümör rezeksiyonu yapılan grup ile sadece primer akciğer tümör rezeksiyonu yapılan grup karşılaştırıldığında; üç yıllık sağ kalım, metastazektomi ve primer akciğer tümör rezeksiyonu yapılan grupta anlamlı derecede yüksek bulunmuştur (\%21.9'a karşıl1k \%6.6, $\mathrm{p}=0.034$ ). Bizim çalışmamızda sadece metastazektomi yapılan grup alındığı için bu karşılaştırma yapılamamıştır.

Kombine tedavilerin tek başına cerrahi tedaviye göre sağ kalımı uzattıgını gösteren çalışmalar da vardır. Saito ve $\operatorname{ark}^{15}$ yaptığı çalışmaya baktığımızda BM'lı olgularda cerrahi sonrası TBRT'nin tek başına cerrahiye göre anlamlı bir şekilde sağ kalım avantajı sağladığı görüldü. Bizim çalışmamızda da postoperatif TBRT alan hastaların sağkalım süresi literatürle uyumluydu. Kranial metastazlı olgularda ölümler en sık santral sinir sistemi progresyonuna bağlı olsa da kranial lezyonda RT ve cerrahi ile lokal kontrol sağlanan hastalarda genellikle ölümler ekstrakranial hastalığın progresyonuna bağlı olarak meydana gelmektedir. $^{16,17}$

Son y1llarda akciğer kanseri özelliklede adenokarsinom alt tipinde; Epidermal growth faktör reseptör (EGFR) mutasyonları ve ekinoderm-miktotubulasosesiye protein 4 (EMLK4) ile anaplastik lenfoma kinaz (ALK) arasındaki füzyonların, ROS1 mutasyonları ve diğer nadir görülen mutasyonların keşfedilmesi ve bu mutasyonlara yönelik(erlotinib, afatinib, gefitinib, krizotinib ve alektinibvs) ajanların kullanılması hastaların prognoz ve yaşam kalitesini kemoterapi ve palyatif tedavilere göre arttırmıştır ${ }^{18-20}$. Çalışmamızda hastalarımızın hiç biri hedefe yönelik ajanları kulla- 


\section{A. Deligönül, ark.}

namamıştır. Bunun sebebi ise o dönemde ilaçların ödenme koşulları ve maliyetlerinin pahalı olması bazı ilaçların ise henüz kullanıma sunulmamasından kaynaklanmıştır.

Çalışmamızın kısıtlı yanlarına baktığımızda; hasta sayısının az olması, sadece metastazektomi yapılanların dahil edilmesi, karşılaştırma kolunun olmaması olarak sayabiliriz.

\section{Sonuç}

Sonuç olarak KHDAK Beyin Metastazı gelişen hastaların uzun süreli sağ kalımı nadirdir ve seçilmiş hasta gruplarında cerrahi tedavi ile lokal kontrol sağlandıktan sonra RT, sistemik tedavilerin uygulanması hastaların yaşam süresini uzatabilir ve hayat kalitesini arttırabilir.

\section{Kaynaklar}

1. Siegel RL, Miller KD, Jemal A. Cancerstatistics, 2018. CA Cancer J Clin. 2018Jan;68(1):7-30.

2. Bovi J.A., White J. Radiationtherapy in theprevention of brainmetastases. Curr. Oncol. Rep. 2012;14:55-62

3. Sperduto PW, Chao ST, Sneed PK et al. Diagnosis specificprognosticfactors, indexes, andtreatmentoutcomesforpatientswithnewlydiagnosedbrainmetastases: amultiinstitutionalanalysis of 4,259 patients. Int $\mathrm{J}$ RadiatOncolBiolPhys.2010 Jul 1;77(3):655-61

4. Langer CJ, Mehta MP. Currentmanagement of brainmetastases, with a focus on systemicoptions. J ClinOncol 2005;23:6207-19.

5. Vecht CJ, Haaxma-Reiche H, Noordijk EM et al. Treatment of singlebrainmetastasis: radiotherapyaloneorcombinedwithneurosurgery? AnnNeurol. 1993 Jun;33(6):583-90

6. Eichler AF, Loeffler JS. Multidisciplinarymanagement of brainmetastases. Oncologist 2007;12:884-98.

7. Bonnette P, Puyo P, Gabriel C, et al. Surgicalmanagement of non-smallcelllungcancerwithsynchronousbrainmetastases. Chest 2001;119:1469-75.

8. Getman V, Devyatko E, Dunkler D, et al. Prognosisof patientswithnonsmallcelllungcancerwithisolatedbrainmetastasesundergo- ingcombinedsurgicaltreatment. Eur J CardiothoracSurg 2004;25:1107-13.

9. Billing PS, Miller DL, Allen MS, et al. Surgicaltreatment of primarylungcancerwithsynchronousbrainmetastases. J ThoracCardiovascSurg 2001;122:548-53.

10. Mussi A, Pistolesi M, Lucchi M, et al. Resection of singlebrainmetastasis in non-small-celllungcancer: prognosticfactors. J ThoracCardiovascSurg 1996;112:146-53.

11. Inal $\mathrm{A}$, Kodaz $\mathrm{H}$, Odabas $\mathrm{H}$, et al.Prognosticfactors of patientswhoreceivedchemotherapyaftercranialirradiationfornonsmallcelllungcancerwithbrainmetastases: A retrospectiveanalysis of multicenterstudy (AnatolianSociety of MedicalOncology). J CancerResTher. 2018 Apr-Jun;14(3):578-82

12. Bonnette P, Puyo P, Gabriel C, et al. GroupeThorax. Surgicalmanagement of nonsmallcelllungcancerwithsynchronousbrainmetastases. Chest. 2001 May;119(5):1469-75.

13. Niemiec M, Głogowski M, Tyc-Szczepaniak D, Wierzchowski M, Kępka L. Characteristics of long-termsurvivors of brainmetastasesfromlungcancer. RepPractOncolRadiother. 2011 Feb 1;16(2):49-53.

14. Iwasaki A, Shirakusa T, Yoshinaga Y, Enatsu S, Yamamoto M. Evaluation of thetreatment of nonsmallcelllungcancerwithbrainmetastasisandthe role of risk score as a survivalpredictor. Eur J CardiothoracSurg. 2004 Sep;26(3):488-93.

15. Saito EY, Viani GA, Ferrigno R, et al. Wholebrainradiationtherapy in management of brainmetastasis: resultsandprognosticfactors. RadiatOncol 2006;1:20.

16. Arbit E, Wroński M, Burt M, Galicich JH. Thetreatment of patientswithrecurrentbrainmetastases. A retrospectiveanalysis of 109 patientswithnonsmallcelllungcancer. Cancer 1995;76(5):765-73.

17. Wen PY, Loeffler JS. Management of brainmetastases. Oncology (Williston Park) 1999;13(7):941-54, 957-69.

18. Peters S, Camidge DR, Shaw AT et al. ALEX Trial Investigators. AlectinibversusCrizotinib in Untreated ALK-PositiveNonSmall-Cell LungCancer. N Engl J Med. 2017 Aug 31;377(9):829-38.

19. Yang JC, Wu YL, Schuler $\mathrm{M}$ et al. Afatinibversuscisplatinbasedchemotherapyfor EGFR mutationpositivelungadenocarcinoma (LUX-Lung 3 and LUX-Lung 6): analysis of overallsurvivaldatafromtworandomised, phase 3 trials. LancetOncol. 2015 Feb;16(2):141-51.

20. Gadgeel S, Peters S, Mok T et al. Alectinibversuscrizotinib in treatment-naiveanaplasticlymphomakinase-positive (ALK+) non-small-celllungcancer: CNS efficacyresultsfromthe ALEX study. AnnOncol. 2018 Nov 1;29(11):2214-22. 